THE $11^{\text {TH }}$ EDITION OF

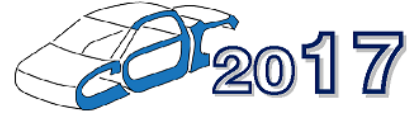

The International Congress of Automotive and Transport Engineering

MOBILITY ENGINEERING AND ENVIRONMENT

November 8-10, 2017

\title{
Determining the theoretical drawbar performance characteristics of tractors, considering the variation of the wheels radii during tractor operation
}

\section{Nastasoiu* and N Ispas}

Department of Automotive and Transport Engineering, Transilvania University of Brasov, 1 Politehnicii Street, Brasov,Romania

*Corresponding author e-mail: m.nastasoiu@unitbv.ro

\author{
Article history \\ Received 10.06.2017 \\ Accepted 25.09.2017 \\ DOI https://doi.org/10.26825/bup.ar.2017.012
}

\begin{abstract}
Ideally, the theoretical drawbar performance characteristics should be identical to the one experimentally obtained. In reality, there are some differences between the two characteristics. One difference lies in that the actual speed of the tractor, which is analytically obtained, is not equal to the actual speed of the tractor that is experimentally obtained. We assume that the actual speed that is obtained on a theoretical basis depends on engine speed, transmission ratio and tractor slip. In reality this speed also depends on the variable value of the tractor wheel radius: for instance, it depends on the tractor variation of weight distribution on the two axles during operation. The paper presents a mathematical model that determines the theoretical drawbar performance characteristics of the wheel tractor taking into account the modification of the wheel radius during operation. The paper also presents applications of the mathematical model developed on tractor MAT 81, constructed in Craiova, Romania. We further examine the calculus systematic errors that may occur when we assume the tractor wheel radius is constant.
\end{abstract}

\section{Introduction. Defining the drawbar performance}

The drawbar performance along with the economic qualities of the tractor for nominal operating conditions and also for all the other conditions are determined with the drawbar performance characteristics. The drawbar performance characteristics is analytically or graphically-analytically built, considering the drawbar pull $F_{t}$ parallel to the ground surface, when the tractor is operated on horizontal ground, under stable operating conditions $(V=$ constant $)$. 
The theoretical drawbar performance characteristics encompasses the graphical representation of the following functions:

- $\delta=f_{1}\left(F_{t}\right)$ - slip considering the drawbar pull;

- $V=f_{2}\left(F_{t}\right)$ - actual speed considering the drawbar pull;

- $\quad P_{t}=f_{3}\left(F_{t}\right)$-drawbar power considering the drawbar pull;

- $c_{t}=f_{4}\left(F_{t}\right)$ - specific fuel consumption, related to the drawbar power, considering the drawbar pull.

To all these curves, the hourly fuel consumption curve is often added: $C=f_{5}\left(F_{t}\right)$.

Except for the slip, all the other parameters depend on the gear and this is why the variation curves are traced for each gear. The drawbar performance characteristic depends on the type of tractor, constructive and operating parameters, and type of ground: concrete road, soil road, agricultural field, stubble field, etc.

The paper presents the method used in order to determine the theoretical drawbar performance characteristics. As compared to traditional methods, this paper takes account of the change of the wheel radius during tractor operation as a consequence of tractor weight distribution on the two axles.

\section{Mathematical modelling of the engine performance curves vs. engine speed}

Under conditions of the engine performance curves vs. engine speed, various mathematical models (for example the "Method of polynomial regression" from MathCAD) are used to obtain the analytical expression of the following curves: $M_{e}=f(n)$ - engine torque, considering the engine speed; $P_{e}=f(n)$ - driving power, considering the engine speed; $c_{e}=f(n)-$ specific fuel consumption, considering the engine speed; $C=f(n)$ - hourly fuel consumption considering the engine speed. In case experimental data are not available, the engine characteristic is approximated with analytical curves of second and third degrees parabolas [1,2].

In practice, the following method for mathematical modelling of the engine characteristics has several advantages [1,2]. The power curve of the engine is approximated with a third degree parabola:

$$
P_{e}=P_{n}\left[\alpha_{1} \frac{n}{n_{n}}+\alpha_{2}\left(\frac{n}{n_{n}}\right)^{2}+\alpha_{3}\left(\frac{n}{n_{n}}\right)^{3}\right] k W,
$$

and the curve of the engine torque is approximated with a second degree parabola:

$$
M_{e}=M_{n}\left[\alpha_{1}+\alpha_{2} \frac{n}{n_{n}}+\alpha_{3}\left(\frac{n}{n_{n}}\right)^{2}\right][N m],
$$

where: $P_{n}$ and $M_{n}-$ nominal power and nominal engine torque; $\alpha_{1}, \alpha_{2}$ and $\alpha_{3}$ coefficients are determined so that the above functions may approximate as accurately as possible the engine performance curves vs. engine speed experimentally obtained. The values of these coefficients depend on the engine elasticity coefficient $c_{e}=n_{m} / n_{n}$, and on the adaptability coefficient $c_{a}=M_{m}$ $/ M_{n}$, (where $n_{m}$ is the speed corresponding to the maximum torque $M_{m}$ ) and may be obtained with the following relations:

$$
\alpha_{1}=\frac{c_{e}^{2}-c_{a}\left(2 c_{e}-1\right)}{\left(c_{e}-1\right)^{2}} ; \quad \alpha_{2}=\frac{2 c_{e}\left(c_{a}-1\right)}{\left(c_{e}-1\right)^{2}} ; \quad \alpha_{3}=-\frac{c_{a}-1}{\left(c_{e}-1\right)^{2}} .
$$

The following relation is established between these coefficients: $\alpha_{1}+\alpha_{2}+\alpha_{3}=1$.

The governor curve of the engine performance curves vs. engine speed shows that the dependency $M_{e}=f(n)$ is linear (a line that crosses the coordinates $\left(n_{n}, M_{n}\right)$ and $\left(n_{g}, 0\right)$ ) and, as a result,

$$
M_{e}=M_{n} \frac{n_{g}-n}{n_{g}-n_{n}} \quad[N m]
$$


where: $n_{g}$ is the idle power-torque-speed, $n_{g}=(1.06 \ldots 1.1) n_{n} ; n_{n}-$ nominal speed.

Various analytical expressions are also used for the determination of the specific fuel consumption. For instance, for direct injection diesel engines, the fuel consumption curve is quite accurately described by the function:

$$
c=c_{n}\left[1.55-1.55 \frac{n}{n_{n}}+\left(\frac{n}{n_{n}}\right)^{2}\right]
$$

where $c_{n}$ is the specific fuel consumption, corresponding to the nominal power, in $\mathrm{g} /(\mathrm{kWh})$.

The specific fuel consumption under nominal conditions may be approximately determined with the relation: $c_{n}=1.05 \cdot c_{\min }$, in $\mathrm{g} /(\mathrm{kWh})$.

On the uncontrolled curve by the speed governor the hourly fuel consumption, in $\mathrm{kg} / \mathrm{h}$, is determined with the relation:

$$
C=10^{-3} c P_{e} .
$$

The governor curve of the engine performance curves vs. engine speed shows that the hourly fuel consumption has a linear variation according to time and it is determined with the relation:

$$
C=C_{g}+\frac{C_{n}-C_{g}}{P_{n}} P_{e}
$$

If for a given engine the hourly consumption $C_{g}$ at an idle engine is not known, we can consider $C_{g}=(0.25 \ldots 0.35) C_{n}$ and $C_{n}=c_{n} P_{n} / 1000$.

The governor curve of the engine performance curves vs. engine speed shows that the specific fuel consumption, in $\mathrm{g}(\mathrm{kWh})$, is determined with the relation:

$$
c=10^{3} \mathrm{C} / P_{e} \text {. }
$$

\section{Determining the tractive effort and the drawbar pull $[1,2,3]$}

The drawbar pull $F_{t, j}$, in a particular gear $j$, is calculated from the balance equation of forces on horizontal ground, under stable operating conditions $(v=$ const. $)$ and is written as follows:

$$
F_{t, j}=\frac{\pi}{30} \cdot \frac{n_{n} \eta_{t r}}{v_{t n, j}} \cdot M_{e}-f G \quad[N] ;
$$

where: $\eta_{t r}$ - transmission efficiency; $v_{t n, j}$ - theoretical speed in a particular gear $j$, under nominal engine condition, in $\mathrm{m} / \mathrm{s} ; f$-rolling resistance coefficient; $G$-tractor operating weight, in $\mathrm{N}$.

The tractive effort $F_{m, j}$ is determined from the balance equation of forces under the above mentioned conditions:

$$
F_{m, j}=F_{t, j}+f G \quad[N] .
$$

\section{Mathematical modelling of the interaction between the running gear system and the ground $[1,2]$}

The wheel slip $\delta$ best characterizes the interaction between the running gear system and the ground. This parameter depends on the specific tractive effort defined by the tractive effort $F_{m}$ and the adhesive weight $G_{a}$ ratio:

$$
\varphi_{m}=\frac{F_{m}}{G_{a}}=\frac{F_{m}}{\lambda_{m} G},
$$

where: $\lambda_{m}$-adhesive weight coefficient (we consider $\lambda_{m}=0.8$, for $4 \times 2$ tractors and $\lambda_{m}=1$, for $4 \times 4$ tractors); $G$-total weight of the tractor.

The parameter $\varphi_{m}$ varies from $\varphi_{m}=0$, when $F_{m}=0$, to $\varphi_{m \max }=\varphi$, value corresponding to total slip, $\delta=1$, known as adhesive coefficient. 
The slip $\delta=f\left(\varphi_{m}\right)$ may be accurately calculated with the following second order function, underscoring that within the range $\varphi_{m}=0 \ldots 0.5 \varphi$ the function is considered linear $\left(\delta=m \varphi_{m}, m\right.$ being the angular coefficient of the line):

$$
\delta=\frac{A \varphi_{m}-B \varphi_{m}^{2}}{D-\varphi_{m}},
$$

where coefficients $A, B, D$ are calculated with the relations:

$$
A=\frac{3 m \varphi}{4} ; \quad B=\frac{m}{2} ; \quad D=\varphi+\frac{m \varphi^{2}}{4} .
$$

\section{Determining the rear wheel radius taking account of the radius change during operation $[4,5]$}

In the specialist literature on theory, construction, testing and operation of wheeled tractors, the tractor wheel radius is constant. In practice, the wheel radius changes during the operation of wheeled tractors. For example, as the drawbar pull value increases, the normal load on the two axles changes: it decreases on the front axle and it increases on the rear axle, which entails the change of the wheel radius: the front wheel radius increases and the rear wheel radius decreases.

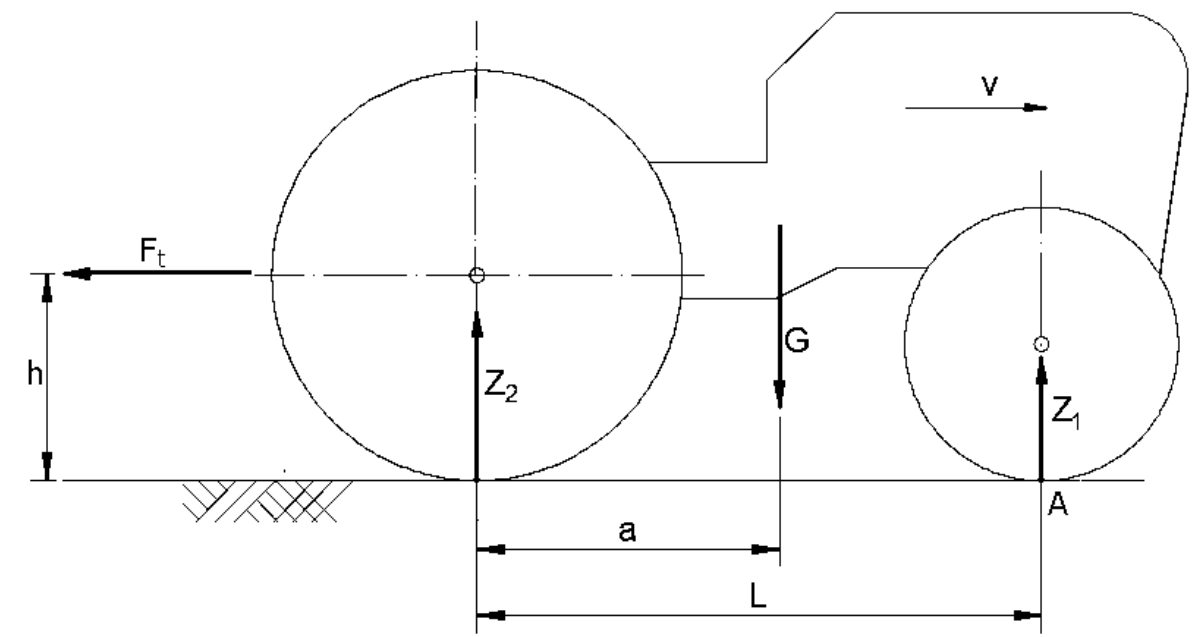

The mathematical modelling of this process is presented below.

Figure 1. Diagram of forces for the calculation of $Z_{2}$ load.

From the equation of moments to point $A$ (figure 1) we can determine the normal load on the rear wheels:

$$
Z_{2} L-G(L-a)-F_{t} h=0,
$$

from where:

$$
Z_{2}=\frac{G(L-a)+F_{t} h}{L} \quad[N] \cdot
$$

The deformation of rear tyres in case of static load:

$$
h=\frac{D_{02}}{2}-r_{2 c} \quad[m] .
$$

where: $D_{02}$ - diameter of the free wheel, in $\mathrm{m}$, with no load acting on it (not even the tyre weight); $r_{2 c}$ - wheel radius used to calculate the theoretical tractor speed, in $\mathrm{m}$.

The radial elastic constant of tyres will be:

$$
\lambda=\frac{z_{02}}{2 h}[N / m],
$$


where $Z_{02}$ is the normal load on the rear axle, in static state, in $\mathrm{N}$.

Under the drawbar pull $F_{t}$, the rear axle is loaded supplementary with the value:

$$
\Delta Z_{2}=Z_{2}-Z_{02} \text {. }
$$

The additional radial deformation of rear tyres will be:

$$
\Delta h=\frac{\Delta z_{2}}{2 \lambda} \quad[m] .
$$

as a result, the value of the rear wheels radius becomes:

$$
\Delta r_{2}=r_{2 c}-\Delta h \text {. }
$$

The decrease in the wheel radius entails the reduction in the tractor speed. The coefficient of speed reduction, resulting from the decrease in the wheel radius, will be:

$$
\Delta V_{r}=\frac{r_{2 c}-\Delta h}{r_{2 c}}=1-\frac{\Delta h}{r_{2 c}} .
$$

\section{Mathematical modelling of the functions defining the drawbar performance characteristics $[1,2]$}

This modelling is based on the methods for mathematical modelling presented in sections $1 \ldots .5$.

6.1. Mathematical modelling of wheel slip considering the drawbar pull: $\delta=f_{1}\left(F_{t}\right)$

We use the modelling from section 4 :

$$
\delta=\frac{A \varphi_{m}-B \varphi_{m}^{2}}{D-\varphi_{m}} .
$$

The specific tractive effort $\varphi_{m}$ is defined with the relations:

$$
\varphi_{m}=\frac{F_{m}}{\lambda_{m} G}=\frac{F_{t}+f G}{\lambda_{m} G}=\varphi_{t}+\frac{f}{\lambda_{m}},
$$

where $\varphi_{t}=F_{t} /\left(\lambda_{m} G\right)$ is the specific drawbar pull effort.

6.2. Mathematical modelling of the actual tractor speed considering the drawbar pull: $V=$ $f_{2}\left(F_{t}\right)$

The actual tractor speed, considering the tractor slip (see section 4) and the variation of wheel radius (see section 5), is calculated with the relation:

$$
V=V_{t}(1-\delta)\left(1-\frac{\Delta h}{r_{2 c}}\right) \quad[\mathrm{m} / \mathrm{s}],
$$

where: $V_{t}-$ tractor theoretical speed, in $\mathrm{m} / \mathrm{s}: V_{t}=\frac{\omega r}{i_{t r}} ; \omega-$ angular velocity of the engine crankshaft, in $\mathrm{s}^{-1} ; r_{2 c}$ - rolling radius of the driven wheels, in $\mathrm{m} ; i_{t r}$ - overall transmission ratio.

6.3. Mathematical modelling of the tractor drawbar power considering the drawbar pull:

$P_{t}=f_{3}\left(F_{t}\right)$

The drawbar power $P_{t}$ is determined with the relation:

$$
P_{t}=F_{t} V \quad[\mathrm{~W}] \text { or } P_{t}=F_{t} V 10^{-3}[\mathrm{~kW}]
$$

where: $F_{t}$ - drawbar pull, in $\mathrm{N}, V$ - actual speed, in $\mathrm{m} / \mathrm{s}$.

6.4. Mathematical odeling of the specific fuel consumption, related to the drawbar power, considering the drawbar pull: $c_{t}=f_{4}\left(F_{t}\right)$ 
The specific fuel consumption, related to the tractor drawbar power, is determined by using its defining relation:

$$
c_{t}=\frac{10^{3} \mathrm{C}}{P_{t}} \quad[\mathrm{~g} /(\mathrm{kWh})] .
$$

The hourly fuel consumption $C$, in $\mathrm{kg}$, (optional parameter in the drawbar performance characteristics) is mathematically modelled by using the corresponding relations from section 2 .

\section{Mathematical modelling of the tractor tractive efficiency: $\eta_{t}=\boldsymbol{f}_{5}\left(\boldsymbol{F}_{\boldsymbol{t}}\right)$}

The mathematical modelling of the tractive efficiency is grounded in the use of the defining relation, that is the tractive efficiency $\eta_{t}$ is equal to the ratio between the drawbar power $P_{t}$ (useful power) and the actual engine power $P_{e}$ (consumed power). The following sequence of equivalent relations is obtained $[1,2]$ :

$$
\eta_{t}=\eta_{t r}(1-\delta) \Delta V_{r}\left(1-\frac{R_{r}}{F_{m}}\right)=\eta_{t r}(1-\delta) \Delta V_{r}\left(1-\frac{f G}{F_{t}+f G}\right)=\frac{\eta_{t r}(1-\delta) \Delta V_{r}}{1+f /\left(\lambda_{m} \varphi_{t}\right)} .
$$

where $\eta_{t r}$ - transmission efficiency.

\section{Applications of the mathematical model elaborated}

Figures 2...5 illustrate graphical representations of the mathematical model developed. The applications are carried out for the tractor MAT 81 that has an engine nominal power of $58 \mathrm{~kW}$ (manufactured at MAT Craiova), with front tyres type 11.2 R 24 and rear tyres type 16.9 R 30, with total operating weight of $3885 \mathrm{~kg}$, with 24 gears, ranging from 0.5 to $37.8 \mathrm{~km} / \mathrm{h}$. These figures represent all the parameters that define the drawbar performance characteristics (see section 1).

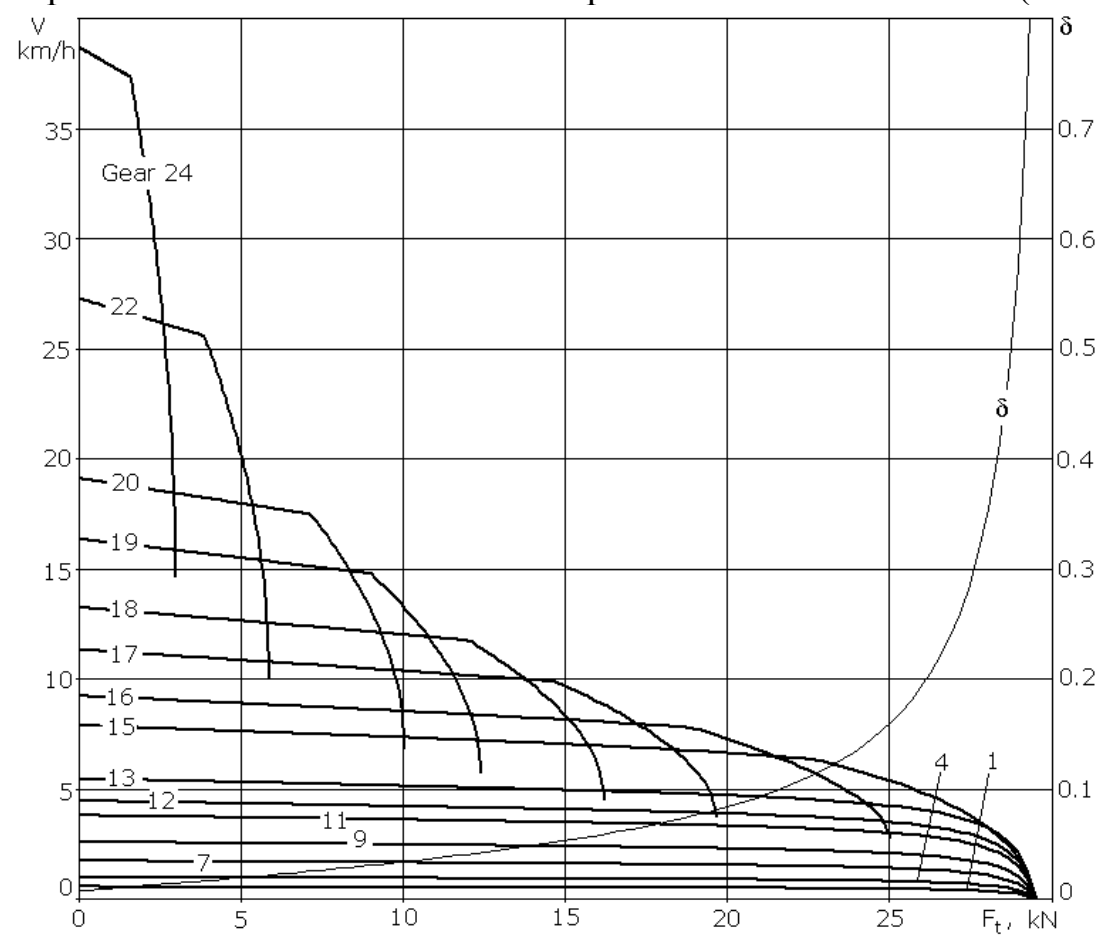

Figure 2. Variation of actual speed $V$ and wheel slip $\delta$ considering the drawbar pull $F_{t}$. 


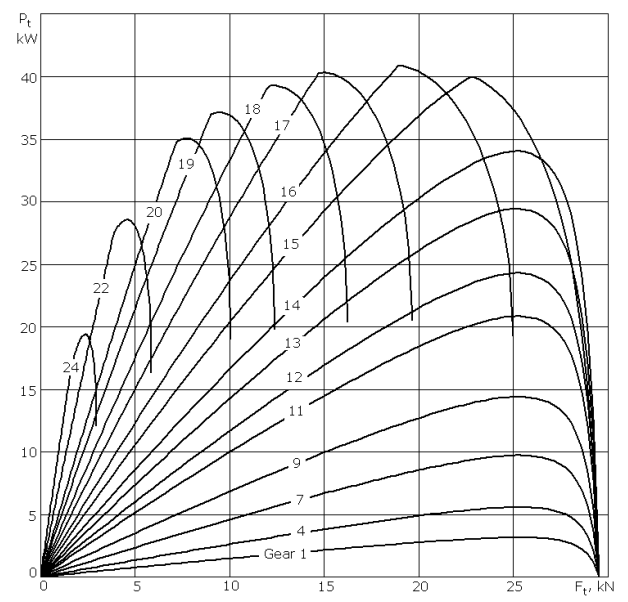

Figure 3. Variation of drawbar power $P_{t}$ considering the drawbar pull $F_{t}$.

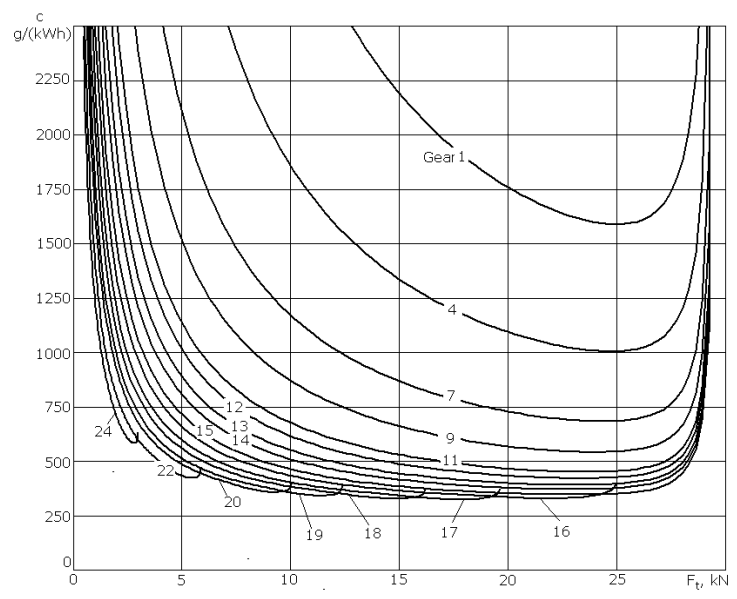

Figure 4. Variation of the specific fuel consumption $c_{t}$, related to the drawbar power $P_{t}$, considering the drawbar pull $F_{t}$.

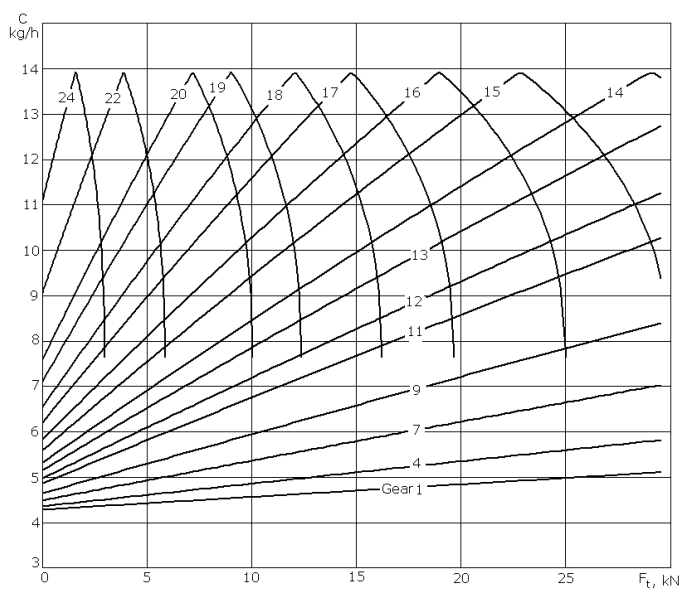

Figure 5. Variation of the hourly fuel consumption $C$ considering the drawbar pull $F_{t}$.

Figure 6 presents the graph of the function $\Delta V_{r}=f\left(F_{t}\right)$ which represents the coefficient of tractor speed reduction as a result of a decrease in the rear wheel radius as the drawbar pull increases. This coefficient is equivalent to a systematic calculation error in case the wheel radius is 
constant in the analytical calculation. In the case analysed this coefficient varies from zero, when $F_{t}$ $=0$, to 0.97 , when $F_{t}=F_{t \max }$, which corresponds to a calculation error of $0 \ldots 3 \%$.

It is known that the tractive efficiency $\eta_{t}$ is a synthetic evaluating indicator of tractors drawbar performance. In figure 7 we evaluate on an intuitive, qualitative and quantitative basis the calculation error that occurs when the wheel radius is constant during operation.

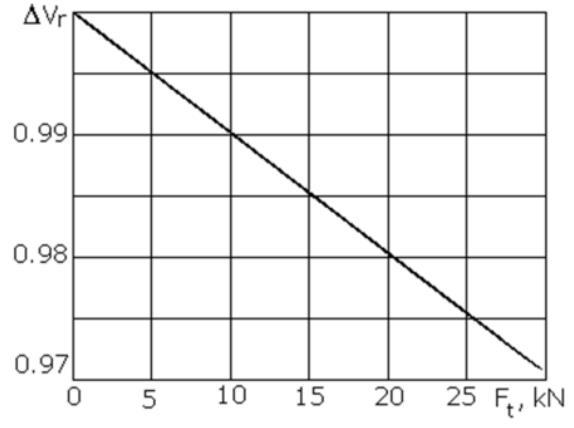

Figure 6. Variation of the coefficient of speed reduction $\Delta V_{r}$ considering the drawbar pull $F_{t}$.

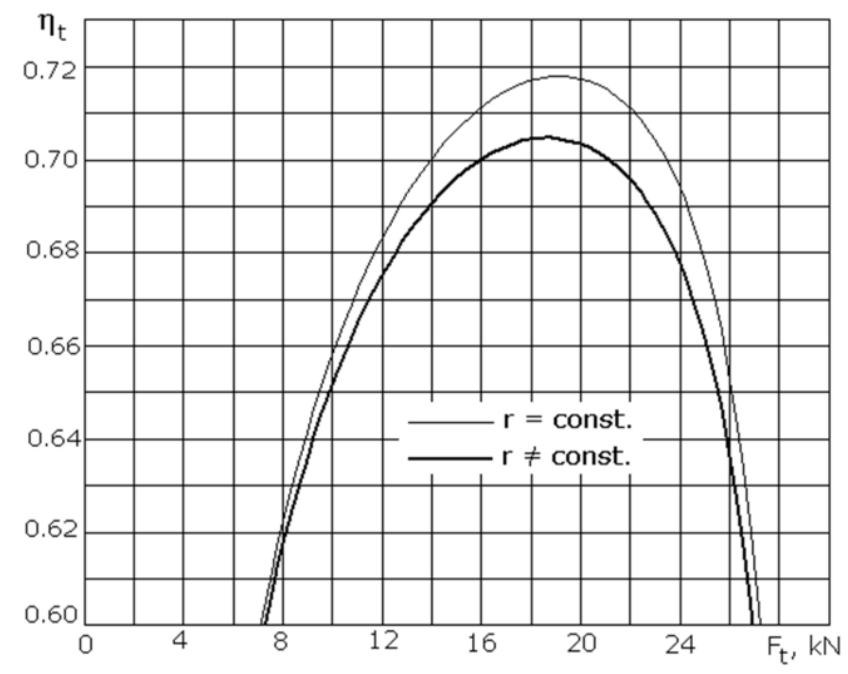

Figure 7. Variation of the tractive efficiency $\eta_{t}$, considering the drawbar pull $F_{t}$, in two cases: $r=$ const., $r \neq$ const.

\section{Conclusions}

The calculation algorithm elaborated to calculate the theoretical drawbar performance characteristics of wheeled tractors is highly generalized: it can be applied to any type of twowheel-drive or four-wheel-drive tractors. As compared to current mathematical models, in the mathematical model elaborated in this paper the wheel radius is considered to be a variable parameter: The radius value changes as the tractor weight is distributed on the two axles during operation.

The application of the calculation algorithm elaborated for the tractor MAT 81 leads to the conclusion that providing the wheel radius is constant, a calculation error of $0 \ldots 3 \%$, occurs in the analytical calculation of the drawbar performance characteristics, considering the drawbar pull.

\section{References}

[1] Nastasoiu S, Andreescu C, Popescu S, Fratila G and Cristea D 1983 Tractoare (Bucureşti: Editura Didactică şi Pedagogică)

[2] Nastasoiu M and Padureanu V 2004 Tractoare. Determinarea performanţelor de tractiune şi economice (Braşov: Editura Universităţii Transilvania)

[3] Nastasoiu M, Padureanu V, Florea D and Nastasoiu S 1999 Metodica incercarii tractoarelor $4 \times 4$ in vederea stabilirii performantelor de tractiune si economice ale acestora (Braşov: Proc. IXth Int. Conf. CONAT'99, vol. III) p 99

[4] Nastasoiu M and Ispas N 2016 Simultaneous Influences of Tyre Pressure and Steering Geometry upon the Theoretical Speed Ratio in the Running Gear System of Four-Wheel Drive Tractors (Chiru A and Ispas $\mathrm{N}$ eds. Proc. of the International Congress of Automotive and Transport Engineering CONAT 2016, vol. 1, Springer International Publishing Switzerland 2017) p 331

[5] Nastasoiu M and Ispas N 2016 Influence of Tyre Pressure and Weight Distribution on Axles on the Theoretical Speed Ratio in the Running Gear System of Four-Wheel Drive Tractors (Andreescu $\mathrm{C}$ and Clenci A eds. Proc. of the European Automotive Congress EAEC-ESFA 2015, vol. 2, Springer International Publishing, Cham 2016) p 695-701. 